Research Article

\title{
Compatibility of Functionalized Graphene with Polyethylene and Its Copolymers
}

\author{
Hyeon Myeong Seo, Jin Ho Park, Trung Dung Dao, and Han Mo Jeong \\ Department of Chemistry, Energy Harvest-Storage Research Center, University of Ulsan, Ulsan 680-749, Republic of Korea \\ Correspondence should be addressed to Han Mo Jeong; hmjeong@mail.ulsan.ac.kr
}

Received 1 July 2013; Accepted 16 September 2013

Academic Editor: R. M. Mehra

Copyright ( 2013 Hyeon Myeong Seo et al. This is an open access article distributed under the Creative Commons Attribution License, which permits unrestricted use, distribution, and reproduction in any medium, provided the original work is properly cited.

The compatibility of polyethylene (PE) with a functionalized graphene sheet (FGS), which was prepared by the thermal reduction of graphite oxide, was examined in this study. The dispersion of the FGS in the PE was improved as the molecular weight of the PE was decreased. The PE copolymers containing polar comonomers such as maleic anhydride or acrylic acid exhibited better compatibility with FGS than the PE homopolymers. The compatibility of the FGS with PE copolymers containing small amounts of comonomers, which have a solubility parameter slightly larger [up to approximately $0.5\left(\mathrm{~J} / \mathrm{cm}^{3}\right)^{1 / 2}$ ] than that of PE itself, was better than the compatibility of both the PE and PE copolymers containing larger amounts of comonomers. The morphology, electric conductivity, and tensile properties of FGS/PE copolymer/PE nanocomposites showed that the copolymers with a solubility parameter slightly larger than that of PE effectively served as a compatibilizer in FGS/PE nanocomposites.

\section{Introduction}

Nanocomposites composed of polymer matrices and nanosize fillers have attracted considerable technological and scientific attention because many physical properties of these matrix polymers, such as the electrical, mechanical, barrier, and flame-retarding properties, can be improved significantly with small amounts of fillers, in comparison to conventional composites. The unique properties of the nanocomposites stem not only from inherent properties of the nanofillers, but also from the maximized interfacial contact and interactions between the nanofiller and the polymer matrix. Therefore, the chemical structure of both the filler surface and the matrix polymer should be tailored to optimize the compatibility between the nanofiller and the matrix polymer in order to obtain a high performance nanocomposite [1-4].

Graphene, a single-atom-thick, two-dimensional sheet composed of $s p^{2}$ bonded carbon atoms arranged in a honeycomb structure, holds great promise for the preparation of high performance nanocomposites because it has an extremely high surface area (as high as $2,600 \mathrm{~m}^{2} / \mathrm{g}$ ), a high aspect ratio, and superior physical properties. It has a Young's modulus of $1 \mathrm{TP}$, electrical conductivity of $6,000 \mathrm{~S} / \mathrm{cm}$, and thermal conductivity of $5,000 \mathrm{~W} / \mathrm{m} \cdot \mathrm{K}[2-5]$.

Flake type graphenes can be prepared effectively in bulk by the rapid heating of graphite oxide (GO) powders because $\mathrm{CO}_{2}$ gas is generated through the thermal decomposition of the oxygen-containing groups of GO. Therefore, the thermally-reduced GO sheets are simultaneously exfoliated into individual graphene sheets by the instantaneous $\mathrm{CO}_{2}$ gas pressure build up in the gallery between the sheets [6]. This method is economical and ecofriendly because it does not use any solvent for the reduction. These exfoliated graphene sheets are normally few-layer graphenes with specific surface areas ranging from 400 to $1500 \mathrm{~m}^{2} / \mathrm{g}$, according to Brunauer, Emmett, and Teller (BET) measurements using nitrogen adsorption in the dry state $[3,7]$. These exfoliated sheets are called functionalized graphene sheets (FGSs) because they contain some of the oxygen-containing functional groups including epoxy and hydroxyl groups even after the thermal reduction [8]. Therefore, they disperse finely in polar solvents and polymers [7, 9-11].

Electrically conductive composites made of polymers and conducting fillers have been extensively investigated 
in the past few decades $[1,2,4]$. These materials can be utilized as antistatic or electromagnetic shielding materials to prevent damage to electronics by electrostatic discharge or electromagnetic interference. Polyethylene (PE) is a typical general-purpose polymer which displays good mechanical properties and high chemical resistance. Therefore it can be used effectively at various applications such as a packaging material for electronics if modified to have improved electrical conductivity $[12,13]$. Graphene can be used as an efficient conductive filler for the modification, because it has high electric conductivity, surface area, and aspect ratio. However, graphenes are difficult to disperse in apolar polyolefins such as PE [3] and thus a high graphene loading fraction is necessary to provide a composite having the properly enhanced electrical conductivity. Normally a high filler loading deteriorates mechanical properties and processability and increases composite density. Therefore, proper modification of graphene, polyethylene, or another appropriate compatibilizer is necessary for fine dispersion of graphene. For example, Kuila et al. functionalized graphene with long alkyl groups by using the reaction of GO and long alkyl amine, followed by subsequent chemical reduction, in order to enhance the compatibility of graphene with linear low density polyethylene (LLDPE) [14]. Some previous studies have focused on graphite nanoplatelet (GNP)/PE nanocomposites [15-19]. The GNPs prepared by exfoliation of intercalated graphite are normally thicker than FGS and have almost no oxygen-containing functional groups. However, to the best of our knowledge, there is no current study that focuses on FGS/PE nanocomposite. The compatibility of FGS with PE can be modulated by adjusting the structure of the $\mathrm{PE}$ or by using an appropriate compatibilizer. Therefore, in this study, we examined how the compatibility of PE can be adjusted by the molecular weight or by copolymerizing polar moiety such as acrylic acid or maleic anhydride. In addition, the compatibilizing effect of these copolymers in a FGS/PE nanocomposite was also examined, because a proper compatibilizer is in some cases more economical and facile for enhancing compatibility than complicated modification of FGS or PE.

\section{Materials and Methods}

2.1. Materials. Two kinds of PE were supplied from Hanwha Chemical, and two kinds of PE were purchased from Aldrich. Three kinds of poly(ethylene-co-acrylic acid) (PEA) and a poly(ethylene-graft-maleic anhydride) (PEM) were also purchased from Aldrich. The designation code and characteristics of the PEs and the copolymers are shown in Table 1. The number average molecular weight $\left(M_{n}\right)$ and weight average molecular weight $\left(M_{w}\right)$ were measured at $150^{\circ} \mathrm{C}$ by gel permeation chromatography (GPC, Waters, Alliance GPCV2000). Trichlorobenzene was used as the eluent, and polystyrene standard samples were used for the calibration of the molecular weight. The solubility parameters of the polymers in Table 1 were calculated by a group contribution method using Fedors' data [20]. Expandable graphite (ES350 F5, average particle size: $280 \mu \mathrm{m}$ ) purchased from Qingdao
Kropfmuehl Graphite Co., Ltd. (China) was used for the preparation of the FGS.

2.2. Preparation of FGS. Graphite oxide (GO) was prepared using the Brodie method, as described in our previous paper [5]. Elemental analysis demonstrated that the GO composition was $\mathrm{C}_{10} \mathrm{O}_{3.45} \mathrm{H}_{1.58}$. The $\mathrm{GO}$ was thermally reduced at $1100^{\circ} \mathrm{C}$ in a $\mathrm{N}_{2}$ atmosphere by decomposing the oxygencontaining groups of the $\mathrm{GO}$ and generating $\mathrm{CO}_{2}$ gas, thus splitting the GO into individual reduced graphene sheets $[5,6]$. Elemental analysis demonstrated that the FGS composition was $\mathrm{C}_{10} \mathrm{O}_{0.78} \mathrm{H}_{0.38}$, indicating that some oxygencontaining functional groups, such as epoxide or hydroxyl groups, remained even after the thermal reduction [6]. The surface area of the FGS, obtained by a BET measurement using nitrogen adsorption in the dry state, was $428 \mathrm{~m}^{2} / \mathrm{g}$. The number average particle size of the FGS was measured using a particle size analyzer (Beckman Coulter LS 13 320) after suspension in ethanol and was determined to be $8.3 \mu \mathrm{m}$.

\subsection{Preparation of FGS Nanocomposites of PE or PE Copoly-} mer. The nanocomposites were fabricated with a $30 \mathrm{~mL}$ Brabender mixer (W30) connected to a Plasti-Corder (PlastiCorder PL2100). All of the samples were melt compounded at $50 \mathrm{rpm}$ for $10 \mathrm{~min}$. The compounding temperature was $85^{\circ} \mathrm{C}$ for PEM and PEAs, $90^{\circ} \mathrm{C}$ for PE3 and PE4, and $100^{\circ} \mathrm{C}$ for $\mathrm{PE} 1$ and PE2. The compounded samples were compression molded at $80^{\circ} \mathrm{C}$ for PEM and PEAs, at $85^{\circ} \mathrm{C}$ for PE3 and PE4, and at $95^{\circ} \mathrm{C}$ for PE1 and PE2 with a pressure of $9.8 \mathrm{MPa}$, when necessary, for examination.

2.4. Characterization. The nanocomposite films, approximately $30 \mu \mathrm{m}$ thick, were imaged using an Eclipse LV100 (Nikon) optical microscope equipped with an Artcam300MI-DS digital camera.

The electric conductivity of the compression molded samples was measured by a four-point probe system (CMTSR 1000 N, AIT Co. Ltd., of Republic Korea).

Differential scanning calorimetry (DSC) was carried out with a DSC Q20 from TA Instruments at a heating and cooling rate of $20^{\circ} \mathrm{C} / \mathrm{min}$ with $10 \mathrm{mg}$ of the sample. After loading at room temperature, the sample was heated to $130^{\circ} \mathrm{C}$ and then cooled to $-40^{\circ} \mathrm{C}$ to measure the crystallization temperature $\left(T_{c}\right)$ and heat of crystallization $\left(\Delta H_{c}\right)$ of the PE or PE copolymer. It was then heated again to measure the melting temperature $\left(T_{m}\right)$ and heat of fusion $\left(\Delta H_{m}\right)$.

The cryogenically fractured surface of the nanocomposite was observed using a field emission scanning electron microscope (FE-SEM, JEOL JSM-6500F).

The tensile properties were examined with a tensile tester (OTU-2, Oriental TM Co., Korea). The compression molded samples were cut into a microtensile specimen $27 \mathrm{~mm}$ in length, $10 \mathrm{~mm}$ in width, and $0.3 \mathrm{~mm}$ in thickness. The specimen was elongated at a rate of $50 \mathrm{~mm} / \mathrm{min}$. 
TABLE 1: Designation codes and characteristics of the polymers used in this study.

\begin{tabular}{|c|c|c|c|c|c|c|}
\hline \multirow{2}{*}{ Designation code } & \multirow{2}{*}{ Kind of polymer } & \multirow{2}{*}{$\begin{array}{l}\text { Comonomer } \\
\text { content (wt } \%)\end{array}$} & \multicolumn{2}{|c|}{ Molecular weight } & \multirow{2}{*}{$\begin{array}{l}\text { Solubility parameter } \\
\left(\mathrm{J} / \mathrm{cm}^{3}\right)^{1 / 2}\end{array}$} & \multirow{2}{*}{ Trade name } \\
\hline & & & $M_{n}$ & $M_{w}$ & & \\
\hline PE1 & Polyethylene & - & 14,100 & 147,500 & 17.5 & Hanwha 737-LDPE \\
\hline PE2 & Polyethylene & - & 12,600 & 105,900 & 17.5 & Hanwha 963-LDPE \\
\hline PE3 & Polyethylene & - & 5,700 & 28,500 & 17.5 & Aldrich 42779-9 \\
\hline PE4 & Polyethylene & - & 1,600 & 4,000 & 17.5 & Aldrich $42777-2$ \\
\hline PEM & $\begin{array}{l}\text { Poly(ethylene-graft-maleic } \\
\text { anhydride) }\end{array}$ & 0.5 & 2,900 & 6,600 & 17.6 & Aldrich 45662-4 \\
\hline PEA5 & Poly(ethylene-co-acrylic acid) & 5 & 1,800 & 3,900 & 17.9 & Aldrich 42671-7 \\
\hline PEA10 & Poly(ethylene-co-acrylic acid) & 10 & 1,200 & 2,800 & 18.3 & Aldrich 42672-5 \\
\hline PEA15 & Poly(ethylene-co-acrylic acid) & 15 & 700 & 1,500 & 18.8 & Aldrich 44867-2 \\
\hline
\end{tabular}

\section{Results and Discussions}

3.1. Compatibility of FGS with PE or PE Copolymers. Optical microscopy was used to characterize the dispersion of FGS in a nanocomposite on a micrometer scale. Optical microscopy images of nanocomposites containing 0.5 parts FGS per 100 parts $\mathrm{PE}$ or PE copolymer ( $0.5 \mathrm{phr}$ ) are shown in Figure 1 . The single-layer graphene is transparent because it only absorbs $2.3 \%$ of the light intensity, independent of the wavelength in the optical domain. Therefore, the single-layer graphene can barely be observed with an optical microscope. However, the transparency decreases when graphenes are stacked into multilayers or agglomerated. Figures 1(a) and 1(b) show that large black FGS aggregates are dispersed coarsely in PE1 and PE2. The black aggregates become smaller and some of them become translucent, as shown in Figures 1(c) and 1(d). These results show that the dispersion of FGS becomes finer when the molecular weight of the PE is smaller (see Table 1). The $\mathrm{PE}$ chain can more easily penetrate into the space between the FGS sheets during melt compounding when the PE chain length is shorter. In addition, the entropy gain accompanied with mixing, $\Delta S_{m}$ in (1), is larger if the PE molecular weight is lower, which reduces the change in Gibbs free energy accompanying the mixing, $\Delta G_{m}$ in (1), and thus contributes affirmatively to make the mixing thermodynamically feasible. These two kinetic and thermodynamic advantages of low molecular weight PE are the causes of the finer FGS dispersion in a low molecular weight PE matrix:

$$
\Delta G_{m}=\Delta H_{m}-T \Delta S_{m}
$$

Figures 1(e) and 1(f) show that the dispersion of FGS is finer in PE copolymers than in PEs (Figures $1(\mathrm{a})-1(\mathrm{~d})$ ), and the number of translucent FGS aggregates is increased. This result indicates that the incorporation of a small amount of polar moieties, maleic anhydride, or acrylic acid, into the PE chain improved the dispersion of the FGS in the polymer matrix. However, the FGS dispersion became coarser when the acrylic acid content in the PE copolymer was increased further, as illustrated in Figures $1(\mathrm{~g})$ and $1(\mathrm{~h})$. In a twocomponent regular solution, the heat of mixing, $\Delta H_{m}$ is proportional to the square of the solubility parameter difference of the components. Accordingly, FGS and PE copolymers should have similar solubility parameters, which reduce the $\Delta H_{m}$ in (1) and thus contribute affirmatively in making fine mixing thermodynamically feasible [21]. Therefore, the above result that FGS has optimum compatibility with PE copolymers that have a solubility parameter slightly higher [up to approximately $0.5\left(\mathrm{~J} / \mathrm{cm}^{3}\right)^{1 / 2}$ ] than that of PE itself (see Table 1), rather than polymers which have higher or lower solubility parameters, suggests that the solubility parameters of FGS are similar with the optimally compatible PE copolymer.

Table 2 shows that the increase in the electric conductivity of PE1 and PE2 were marginal even with 3.0 phr FGS. However, the percolation threshold where the conductivity increases distinctly lies in the range of 0.5 to $1.5 \mathrm{phr}$ for the nanocomposite of FGS with PE3, PE4, and PE copolymers. In the nanocomposites containing 1.5 phr FGS, the nanocomposites of PEM or PEA5 exhibit better conductivity than those of PE homopolymers or other PEAs. This result also shows that the dispersion of FGS in PE is improved effectively when the chain length is decreased or when PE copolymers have a solubility parameter slightly larger than that of PE homopolymer, as observed by optical microscopy.

In the nanocomposites, the crystallization of matrix polymer can be improved by the nucleating effect of dispersed filler. However, the interaction between the filler and matrix polymer, which hinders rearrangement for crystallization of the matrix polymer, can interfere with the crystallization $[22,23]$. In the nanocomposites of PE1, PE2, PE3, and PE4 (Table 2), the $T_{c}, \Delta H_{c}$, and $\Delta H_{m}$ values generally exhibited an increase and then a decrease as the content of FGS was increased, although there were some exceptions. This result shows that the nucleating effect is dominant at a low FGS content, whereas the hindrance effect is dominant at a high FGS content in the composites. Similar crystallization behavior of PE had previously been reported for mica/high density polyethylene composites [24]. Table 2 also shows that the increases in $T_{c}, \Delta H_{c}$, and $\Delta H_{m}$ are most evident in the 


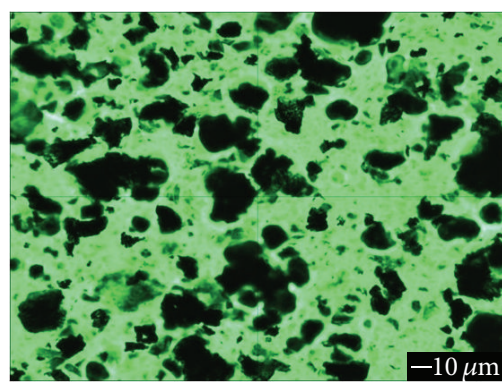

(a)

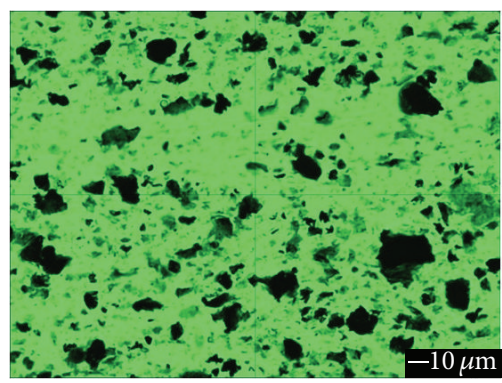

(d)

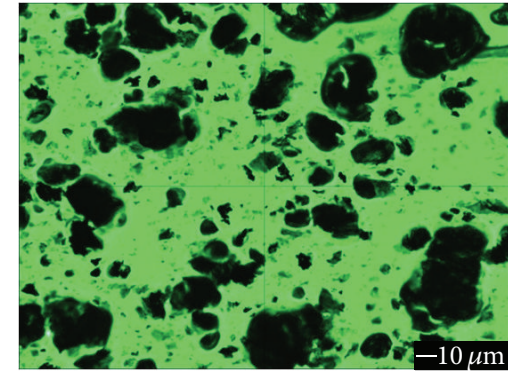

(b)

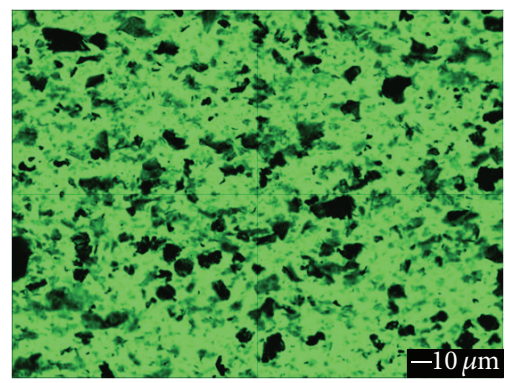

(e)

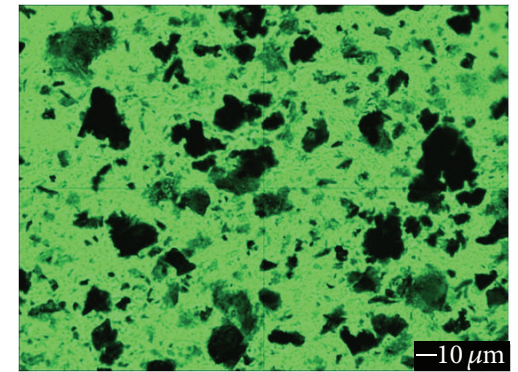

(c)

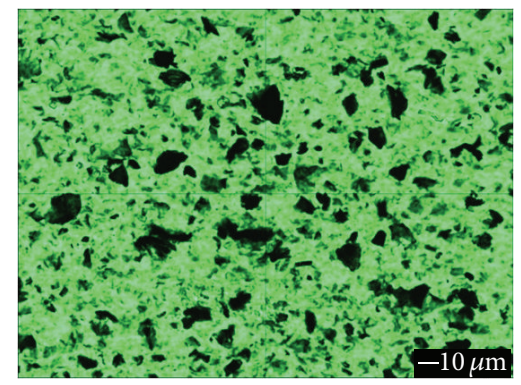

(f)

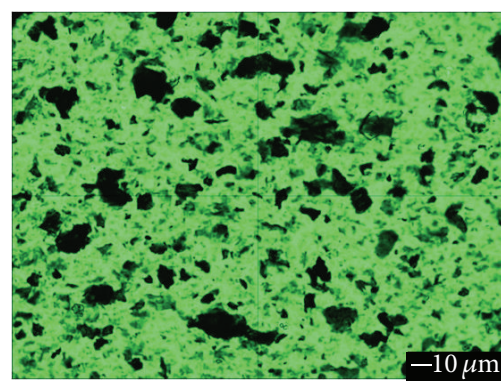

(g)

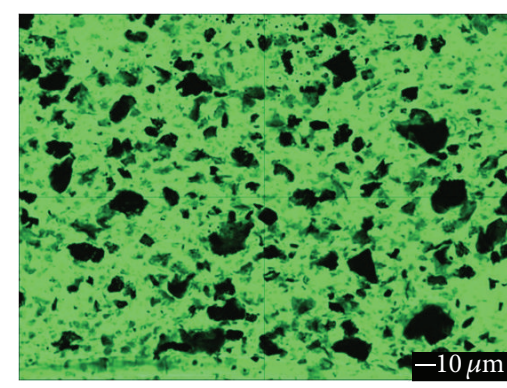

(h)

Figure 1: Optical microscopy images of the nanocomposites of (a) PE1, (b) PE2, (c) PE3, (d) PE4, (e) PEM, (f) PEA5, (g) PEA10, and (h) PEA15 containing 0.5 phr FGS.

FGS nanocomposite of PE4, which has the lowest molecular weight.

As shown in Table 2, all of the $\Delta H_{c}$ and $\Delta H_{m}$ values of the nanocomposites are less than those of the pristine polymers themselves for the nanocomposites of PE copolymers, although the molecular weights of most of them are similar or less than that of PE4. This result demonstrates that the interaction of the copolymers with FGS is stronger than that of $\mathrm{PE}$ due to the polar groups in the copolymer.

3.2. Compatibilizing Effect of the PE Copolymer in FGS/PE Nanocomposites. The compatibilizing effect of PE copolymers on FGS/PE3 nanocomposites containing 0.5 phr FGS was examined with optical microscopy. Figure 2 shows that the dispersion of FGS in the polymer matrix was improved compared to that of Figure 1(c) by the compatibilizing effect of the PE copolymers. The FGS dispersions are finer in Figures 2(a) and 2(b) than those in Figures 2(c) and 2(d), which demonstrates that the compatibilizing effect of PEM or
PEA5 is better than that of PEA10 or PEA15. The compatibility of PEM or PEA5 with FGS was determined to be better than that of PEA10 or PEA15 (Figure 1). In addition, the compatibility of PEM or PEA5 with PE3 will be better than that of PEA10 or PEA15 because they have more similar chemical structures and consequently more similar solubility parameters (Table 1). These are the causes of the better compatibilizing effect.

The SEM image (Figure 3(a)) shows a large heterogeneous particle exhibiting coarse structure in the FGS/PE3 nanocomposite containing 1.5 phr FGS. The magnified image of this particle (Figure 3(b)) shows that this particle is an aggregate of crumpled FGSs. However, in Figure 3(c), the regions showing coarse structure are finely dispersed and, even in those regions, it is not easy to find an aggregate of crumpled FGS (Figure 3(d)). These SEM images also demonstrate that the dispersion of FGS in PE3 was improved by the compatibilizing effect of PEA5.

Table 3 shows that the electric conductivity of the FGS/PE3 nanocomposite containing 1.5 phr FGS increased 


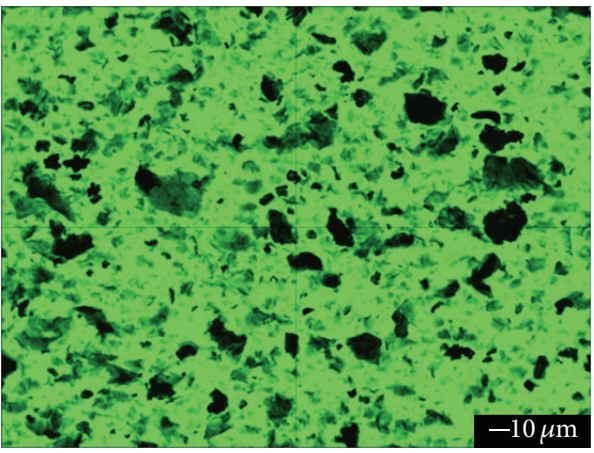

(a)

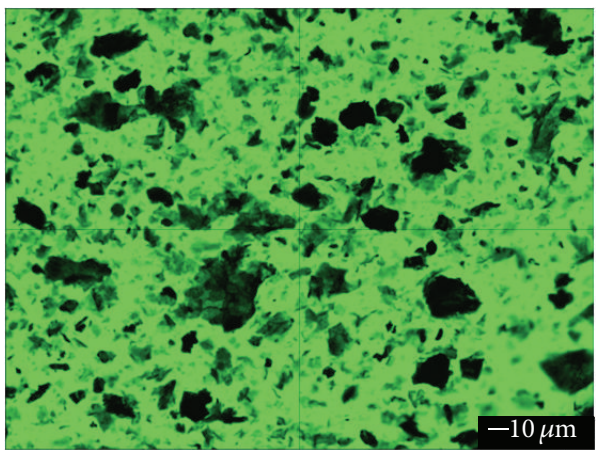

(c)

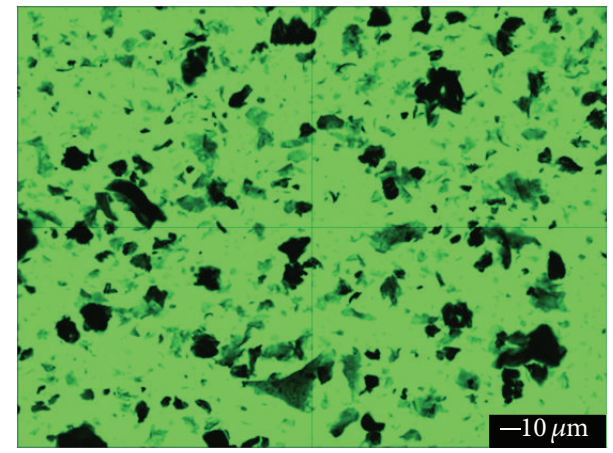

(b)

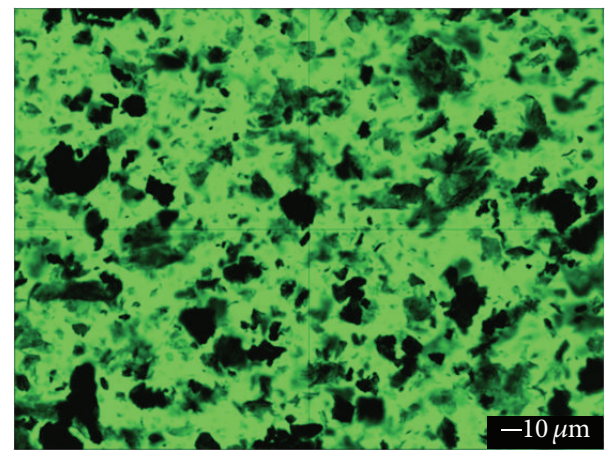

(d)

FIGURE 2: Optical microscopy images of FGS/PE3 (0.5/90 parts) nanocomposites compatibilized with 10 parts (a) PEM, (b) PEA5, (c) PEA10, and (d) PEA15.

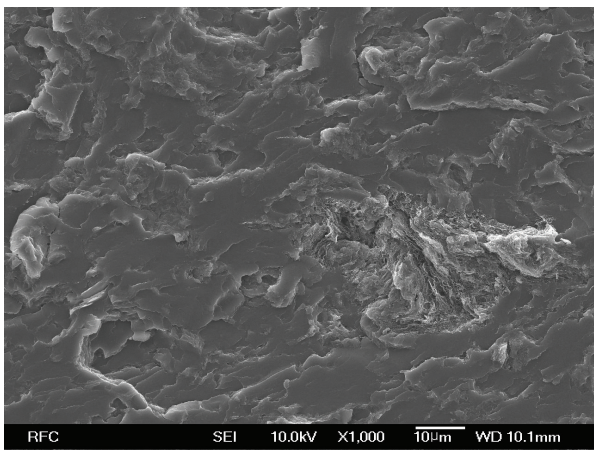

(a)

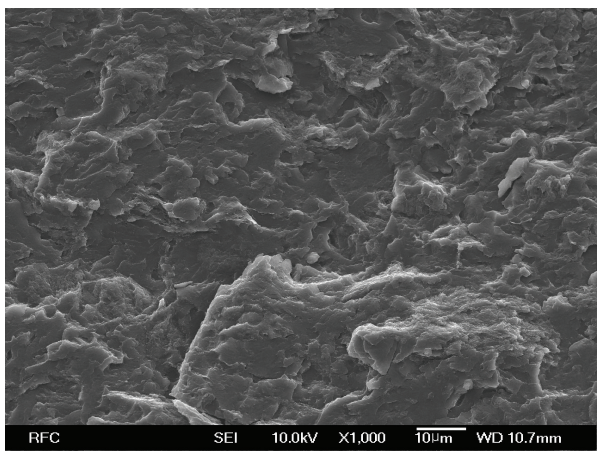

(c)

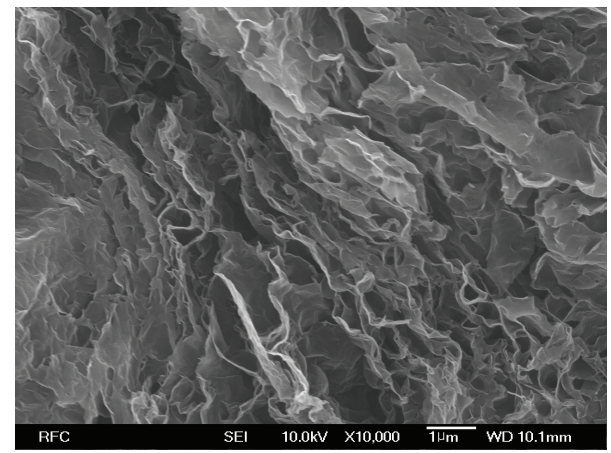

(b)

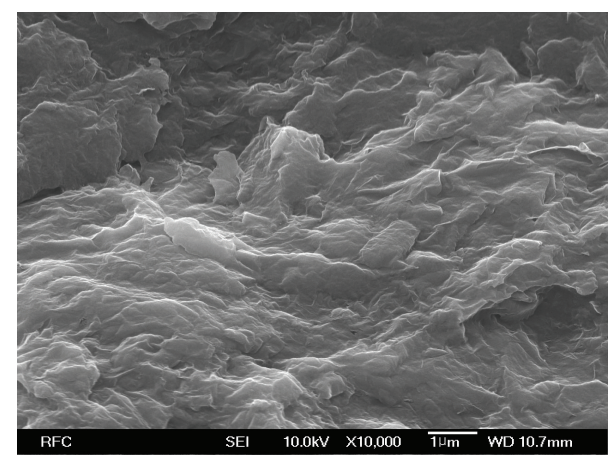

(d)

FIGURE 3: SEM images of cryogenically fractured surface; (a) and (b) FGS/PE3 (1.5/100 parts) nanocomposites, (c) and (d) FGS/PE3/PEA5 (1.5/90/10 parts). 
TABLE 2: Electric conductivity and thermal properties of FGS nanocomposites of PE or PE copolymers.

\begin{tabular}{|c|c|c|c|c|c|}
\hline \multirow[b]{2}{*}{ Composition } & \multirow{2}{*}{$\begin{array}{l}\text { Conductivity } \\
(\mathrm{S} / \mathrm{cm})\end{array}$} & \multicolumn{4}{|c|}{ Thermal properties } \\
\hline & & $\begin{array}{c}T_{c} \\
\left({ }^{\circ} \mathrm{C}\right) \\
\end{array}$ & $\begin{array}{l}\Delta H_{c} \\
(\mathrm{~J} / \mathrm{g})\end{array}$ & $\begin{array}{c}T_{m} \\
\left({ }^{\circ} \mathrm{C}\right) \\
\end{array}$ & $\begin{array}{l}\Delta H_{m} \\
(\mathrm{~J} / \mathrm{g})\end{array}$ \\
\hline FGS/PE1 (0/100) & $1.5 \times 10^{-9}$ & 90.9 & 93.9 & 103.9 & 84.4 \\
\hline FGS/PE1 (0.5/100) & $1.8 \times 10^{-9}$ & 90.6 & 96.6 & 104.2 & 86.0 \\
\hline FGS/PE1 (1.5/100) & $1.8 \times 10^{-9}$ & 89.4 & 75.1 & 104.3 & 70.6 \\
\hline FGS/PE1 (3/100) & $2.1 \times 10^{-9}$ & 88.8 & 80.1 & 103.8 & 76.2 \\
\hline FGS/PE2 (0/100) & $1.2 \times 10^{-9}$ & 94.8 & 103.4 & 107.9 & 94.6 \\
\hline FGS/PE2 (0.5/100) & $1.3 \times 10^{-9}$ & 94.1 & 97.6 & 108.3 & 88.6 \\
\hline FGS/PE2 (1.5/100) & $1.6 \times 10^{-9}$ & 91.9 & 90.6 & 108.2 & 75.7 \\
\hline FGS/PE2 (3/100) & $1.9 \times 10^{-9}$ & 92.9 & 91.9 & 107.4 & 84.6 \\
\hline FGS/PE3 (0/100) & $1.5 \times 10^{-9}$ & 65.4 & 84.9 & 97.7 & 61.0 \\
\hline FGS/PE3 (0.5/100) & $1.8 \times 10^{-9}$ & 83.3 & 85.8 & 97.7 & 74.5 \\
\hline FGS/PE3 (1.5/100) & $5.0 \times 10^{-5}$ & 65.0 & 82.4 & 96.4 & 59.8 \\
\hline FGS/PE3 (3/100) & $2.3 \times 10^{-2}$ & 55.8 & 79.9 & 95.2 & 54.8 \\
\hline FGS/PE4 (0/100) & $1.9 \times 10^{-9}$ & 85.9 & 52.8 & 97.6 & 47.4 \\
\hline FGS/PE4 (0.5/100) & $2.7 \times 10^{-9}$ & 93.2 & 98.5 & 97.7 & 104.9 \\
\hline FGS/PE4 (1.5/100) & $6.2 \times 10^{-5}$ & 91.8 & 113.4 & 103.8 & 112.1 \\
\hline FGS/PE4 (3/100) & $2.5 \times 10^{-2}$ & 93.7 & 102.1 & 103.4 & 92.4 \\
\hline FGS/PEM (0/100) & $2.2 \times 10^{-9}$ & 89.5 & 85.7 & 102.7 & 82.0 \\
\hline FGS/PEM (0.5/100) & $4.0 \times 10^{-9}$ & 83.4 & 53.2 & 95.5 & 55.9 \\
\hline FGS/PEM (1.5/100) & $4.8 \times 10^{-4}$ & 88.6 & 82.9 & 100.7 & 80.5 \\
\hline FGS/PEA5 (0/100) & $1.4 \times 10^{-9}$ & 88.1 & 76.0 & 100.5 & 76.3 \\
\hline FGS/PEA5 (0.5/100) & $2.8 \times 10^{-9}$ & 88.4 & 69.6 & 100.3 & 72.3 \\
\hline FGS/PEA5 (1.5/100) & $4.3 \times 10^{-4}$ & 84.7 & 62.9 & 101.2 & 62.9 \\
\hline FGS/PEA10 (0/100) & $1.8 \times 10^{-9}$ & 81.1 & 53.9 & 95.3 & 56.4 \\
\hline FGS/PEA10 (0.5/100) & $2.5 \times 10^{-9}$ & 82.9 & 52.4 & 95.8 & 54.7 \\
\hline FGS/PEA10 (1.5/100) & $3.2 \times 10^{-4}$ & 68.1 & 31.9 & 84.1 & 26.3 \\
\hline FGS/PEA15 (0/100) & $2.5 \times 10^{-9}$ & 73.9 & 32.1 & 89.6 & 29.4 \\
\hline FGS/PEA15 (0.5/100) & $2.7 \times 10^{-9}$ & 72.3 & 30.5 & 88.3 & 27.9 \\
\hline FGS/PEA15 (1.5/100) & $2.3 \times 10^{-4}$ & 65.0 & 28.3 & 83.3 & 25.8 \\
\hline
\end{tabular}

when PE3 was replaced up to $10 \%$ by PEM or PEA5 due to the compatibilizing effect of the copolymers. However, it decreased again when $15 \%$ of the PE3 was replaced with the copolymers. Furthermore, the electric conductivity of the FGS/PE3 nanocomposite decreased even when less than $10 \%$ PE3 was replaced by PEA10 or PEA15 (Table 3). These results suggest the possibility that the copolymer phase, where FGS is preferentially localized, is separated at the high content of $15 \%$ for PEM or PEA5 and at an even lower content for PEM10 or PEA15 [25].

Table 4 shows that the improvements in the modulus and yield strength of PE3 by FGS are evident through the reinforcing effect of FGS even without any compatibilizer. Greater than twofold increases in the modulus and yield strength due to the addition of 3 phr FGS are much higher than the reinforcing effect observed in
TABLE 3: Electric conductivity of FGS/PE3/PE copolymer nanocomposites.

\begin{tabular}{lc}
\hline Composition & Electric conductivity $(\mathrm{S} / \mathrm{cm})$ \\
\hline FGS/PE3 (1.5/100) & $5.0 \times 10^{-5}$ \\
\hline FGS/PE3/PEM (1.5/95/5) & $9.1 \times 10^{-5}$ \\
FGS/PE3/PEM (1.5/90/10) & $1.6 \times 10^{-4}$ \\
FGS/PE3/PEM (1.5/85/15) & $3.0 \times 10^{-5}$ \\
\hline FGS/PE3/PEA5 (1.5/95/5) & $7.2 \times 10^{-5}$ \\
FGS/PE3/PEA5 (1.5/90/10) & $2.4 \times 10^{-4}$ \\
FGS/PE3/PEA5 (1.5/85/15) & $3.1 \times 10^{-5}$ \\
\hline FGS/PE3/PEA10 (1.5/95/5) & $4.6 \times 10^{-5}$ \\
FGS/PE3/PEA10 (1.5/90/10) & $2.8 \times 10^{-5}$ \\
FGS/PE3/PEA10 (1.5/85/15) & $2.5 \times 10^{-5}$ \\
\hline FGS/PE3/PEA15 (1.5/95/5) & $3.5 \times 10^{-5}$ \\
FGS/PE3/PEA15 (1.5/90/10) & $2.6 \times 10^{-5}$ \\
FGS/PE3/PEA15 (1.5/85/15) & $2.4 \times 10^{-5}$ \\
\hline
\end{tabular}

FGS/PP [3], paraffin-coated GNP/LLDPE [17], or alkyl chainfunctionalized graphene/LLDPE nanocomposites [14]. However, the elongation at break shows a different story. The elongation drastically decreases when reinforced with FGS, as in the FGS/PP nanocomposite [3]. This result shows that the molecular rearrangement of PE3 toward the tensile axis during tensile deformation is strictly inhibited by FGS.

The tensile properties of the PE copolymers were too poor to carry out the tensile test. However, Table 4 shows that the reinforcing effect of FGS in the FGS/PE3 (1.5/100) nanocomposite was improved when $10 \%$ of PE3 was replaced with PE copolymers due to the compatibilizing effect of the replaced copolymers. This reinforcing effect presented in Table 4 was more evident by PEM or PEA5 than by PEA10 or PEA15, which also shows that PEA5 or PEM are better compatibilizers than PEA10 or PEA15 for the FGS/PE nanocomposite.

\section{Conclusions}

The compatibility of FGS with high molecular weight PE was so poor that the nanocomposite prepared by melt compounding did not exhibit the percolation threshold of electric conductivity even though the FGS content was as high as 3.0 phr. The compatibility was improved when the molecular weight of PE was decreased. Small amounts of copolymerized polar monomers, such as maleic anhydride or acrylic acid, also improved the compatibility. However, too much of the polar comonomer decreased the compatibility. The PE copolymers with a solubility parameter slightly larger [up to approximately $0.5\left(\mathrm{~J} / \mathrm{cm}^{3}\right)^{1 / 2}$ ] than that of PE itself showed the optimum compatibility.

The crystallization of the PE in the FGS/PE nanocomposite was enhanced by the FGS due to the nucleating effect. However, in the PE nanocomposites with a high FGS content or in the nanocomposites of the PE copolymers, the crystallinity of the PE or PE copolymers was reduced due to the increased interaction between the FGS and the matrix 
TABLE 4: Tensile properties of FGS/PE3/PE copolymer nanocomposites.

\begin{tabular}{lcccc}
\hline Composition & Modulus $(\mathrm{GPa})$ & Yield strength $(\mathrm{MPa})$ & Tensile strength $(\mathrm{MPa})$ & Elongation at break $(\%)$ \\
\hline PE3 & $2.26 \pm 0.41$ & $3.08 \pm 0.08$ & $4.55 \pm 0.08$ & $21 \pm 3$ \\
\hline FGS/PE3 (0.5/100) & $3.00 \pm 0.12$ & $4.01 \pm 0.13$ & $5.21 \pm 0.09$ & $6 \pm 1$ \\
FGS/PE3 (1.5/100) & $3.64 \pm 0.12$ & $4.84 \pm 0.10$ & $5.61 \pm 0.74$ & $2 \pm 1$ \\
FGS/PE3 (3.0/100) & $4.75 \pm 0.16$ & $6.47 \pm 0.12$ & $9.26 \pm 0.31$ & $4 \pm 1$ \\
\hline FGS/PE3/PEM (1.5/90/10) & $4.03 \pm 0.09$ & $5.53 \pm 0.07$ & $5.86 \pm 0.06$ & $2 \pm 1$ \\
FGS/PE3/PEA5 (1.5/90/10) & $4.59 \pm 0.10$ & $6.61 \pm 0.05$ & $8.24 \pm 0.05$ & $3 \pm 1$ \\
FGS/PE3/PEA10 (1.5/90/10) & $3.33 \pm 0.12$ & $4.58 \pm 0.11$ & $5.62 \pm 0.21$ & $2 \pm 1$ \\
FGS/PE3/PEA15 (1.5/90/10) & $3.51 \pm 0.21$ & $4.88 \pm 0.15$ & $6.26 \pm 0.24$ & $3 \pm 1$ \\
\hline
\end{tabular}

molecules. This interaction hindered the rearrangement of the matrix molecules for crystallization.

The morphology, electric conductivity, and tensile properties of the FGS/PE copolymer/PE nanocomposites showed that the PE copolymers with a solubility parameter slightly larger than that of PE itself effectively served as a compatibilizer for the FGS/PE nanocomposite.

\section{Acknowledgment}

This work was supported by Priority Research Centers Program through the National Research Foundation of Korea (NRF) funded by the Ministry of Education (2009-0093818).

\section{References}

[1] T. K. Das and S. Prusty, "Graphene-based polymer composites and their applications," Polymer-Plastics Technology and Engineering, vol. 52, no. 4, pp. 319-331, 2013.

[2] T. Kuilla, S. Bhadra, D. Yao, N. H. Kim, S. Bose, and J. H. Lee, "Recent advances in graphene based polymer composites," Progress in Polymer Science, vol. 35, no. 11, pp. 1350-1375, 2010.

[3] P. Steurer, R. Wissert, R. Thomann, and R. Mülhaupt, "Functionalized graphenes and thermoplastic nanocomposites based upon expanded graphite oxide," Macromolecular Rapid Communications, vol. 30, no. 4-5, pp. 316-327, 2009.

[4] R. Sengupta, M. Bhattacharya, S. Bandyopadhyay, and A. K. Bhowmick, "A review on the mechanical and electrical properties of graphite and modified graphite reinforced polymer composites," Progress in Polymer Science, vol. 36, no. 5, pp. 638670, 2011.

[5] J. T. Choi, D. H. Kim, K. S. Ryu et al., "Functionalized graphene sheet/polyurethane nanocomposites: effect of particle size on physical properties," Macromolecular Research, vol. 19, no. 8, pp. 809-814, 2011.

[6] M. J. McAllister, J.-L. Li, D. H. Adamson et al., "Single sheet functionalized graphene by oxidation and thermal expansion of graphite," Chemistry of Materials, vol. 19, no. 18, pp. 4396-4404, 2007.

[7] H. Kim and C. W. Macosko, "Processing-property relationships of polycarbonate/graphene composites," Polymer, vol. 50, no. 15, pp. 3797-3809, 2009.

[8] H. C. Schniepp, J.-L. Li, M. J. McAllister et al., "Functionalized single graphene sheets derived from splitting graphite oxide," The Journal of Physical Chemistry B, vol. 110, no. 17, pp. 85358539, 2006.
[9] D. A. Nguyen, Y. R. Lee, A. V. Raghu, H. M. Jeong, C. M. Shin, and B. K. Kim, "Morphological and physical properties of a thermoplastic polyurethane reinforced with functionalized graphene sheet," Polymer International, vol. 58, no. 4, pp. 412417, 2009.

[10] Y. R. Lee, A. V. Raghu, H. M. Jeong, and B. K. Kim, "Properties of waterborne polyurethane/functionalized graphene sheet nanocomposites prepared by an in situ method," Macromolecular Chemistry and Physics, vol. 210, no. 15, pp. 1247-1254, 2009.

[11] T. Ramanathan, A. A. Abdala, S. Stankovich et al., "Functionalized graphene sheets for polymer nanocomposites," Nature Nanotechnology, vol. 3, no. 6, pp. 327-331, 2008.

[12] V. S. Mironov, S. Y. Kim, and M. Park, "Electrical properties of polyethylene composite films filled with nickel powder and short carbon fiber hybrid filler," Carbon Letters, vol. 14, no. 2, pp. 105-109, 2013.

[13] P. G. Ren, Y. Y. Di, Q. Zhang, L. Li, H. Pang, and Z. M. Li, "Composites of ultrahigh-molecular-weight polyethylene with graphene sheets and/or MWCNTs with segregated network structure: preparation and properties," Macromolecular Materials and Engineering, vol. 297, no. 5, pp. 437-443, 2012.

[14] T. Kuila, S. Bose, C. E. Hong et al., "Preparation of functionalized graphene/linear low density polyethylene composites by a solution mixing method," Carbon, vol. 49, no. 3, pp. 1033-1037, 2011.

[15] D. Lahiri, R. Dua, C. Zhang et al., "Graphene nanoplateletinduced strengthening of ultrahigh molecular weight polyethylene and biocompatibility in vitro," ACS Applied Materials and Interfaces, vol. 4, no. 4, pp. 2234-2241, 2012.

[16] X. Jiang and L. T. Drzal, "Reduction in percolation threshold of injection molded high-density polyethylene/exfoliated graphene nanoplatelets composites by solid state ball milling and solid state shear pulverization," Journal of Applied Polymer Science, vol. 124, no. 1, pp. 525-535, 2012.

[17] S. Kim, J. Seo, and L. T. Drzal, "Improvement of electric conductivity of LLDPE based nanocomposite by paraffin coating on exfoliated graphite nanoplatelets," Composites A, vol. 41, no. 5, pp. 581-587, 2010.

[18] Y.-C. Li and G.-H. Chen, "HDPE/expanded graphite nanocomposites prepared via masterbatch process," Polymer Engineering and Science, vol. 47, no. 6, pp. 882-888, 2007.

[19] G. Chen, X. Chen, H. Wang, and D. Wu, "Dispersion of graphite nanosheets in polymer resins via masterbatch technique," Journal of Applied Polymer Science, vol. 103, no. 6, pp. 3470-3475, 2007.

[20] D. W. van Krevelen and P. J. Hoftyzer, Properties of Polymers, Elsevier, Amsterdam, The Netherlands, 1976. 
[21] S. Park, J. An, I. Jung et al., "Colloidal suspensions of highly reduced graphene oxide in a wide variety of organic solvents," Nano Letters, vol. 9, no. 4, pp. 1593-1597, 2009.

[22] H. B. Lee, A. V. Raghu, K. S. Yoon, and H. M. Jeong, "Preparation and characterization of poly(ethylene oxide)/graphene nanocomposites from an aqueous medium," Journal of Macromolecular Science B, vol. 49, no. 4, pp. 802-809, 2010.

[23] W. Kai, Y. Hirota, L. Hua, and Y. Inoue, "Thermal and mechanical properties of a Poly( $\varepsilon$-caprolactone)/graphite oxide composite," Journal of Applied Polymer Science, vol. 107, no. 3, pp. 1395-1400, 2008.

[24] L. Chen, Y.-F. Xiang, K. Wang, Q. Zhang, R.-N. Du, and Q. Fu, "Effects of matrix molecular weight on structure and reinforcement of high density polyethylene/mica composites," Chinese Journal of Polymer Science (English Edition), vol. 29, no. 3, pp. 377-389, 2011.

[25] F. Gubbels, S. Blacher, E. Vanlathem et al., "Design of electrical conductive composites: key role of the morphology on the electrical properties of carbon black filled polymer blends," Macromolecules, vol. 28, no. 5, pp. 1559-1566, 1995. 

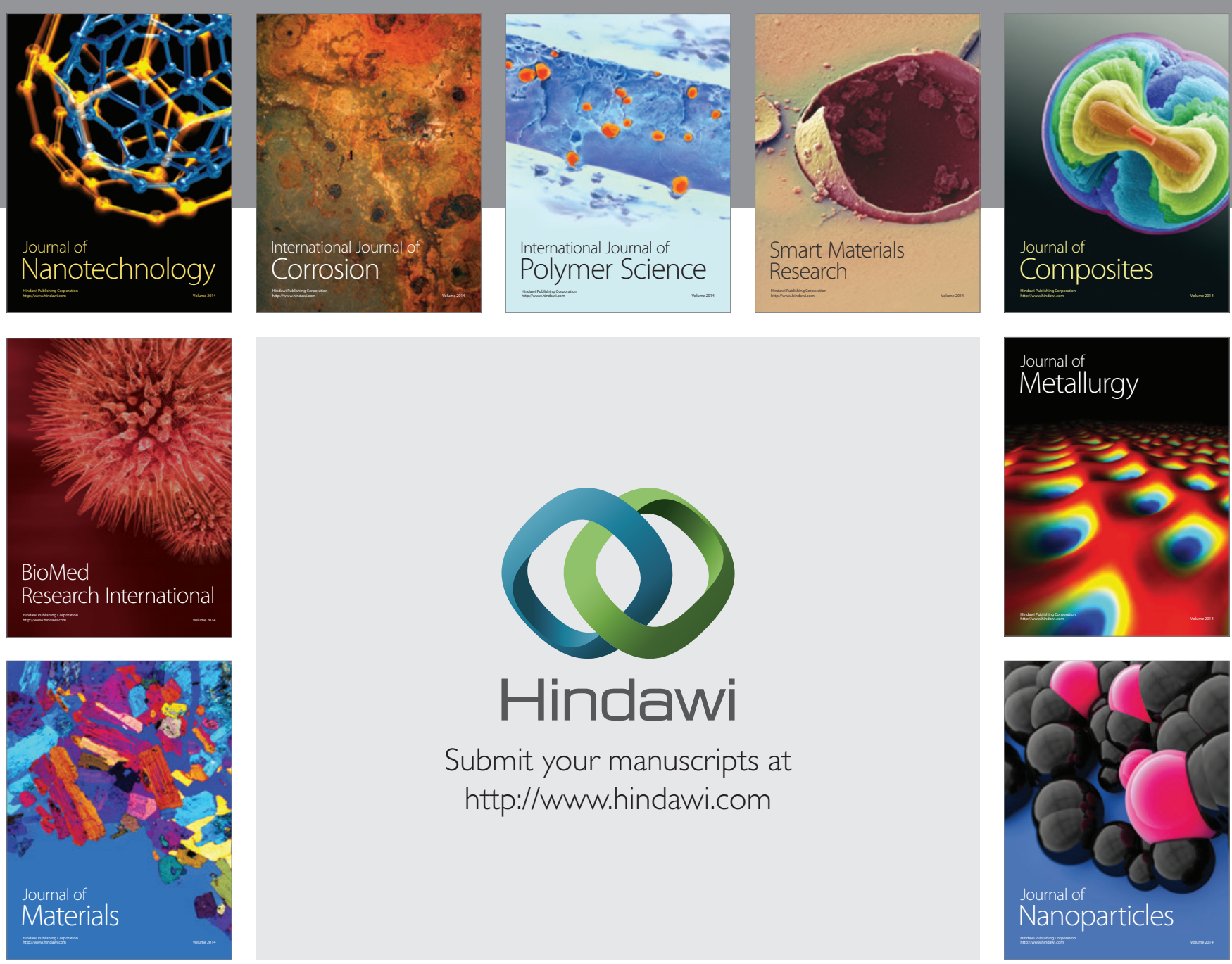

Submit your manuscripts at http://www.hindawi.com
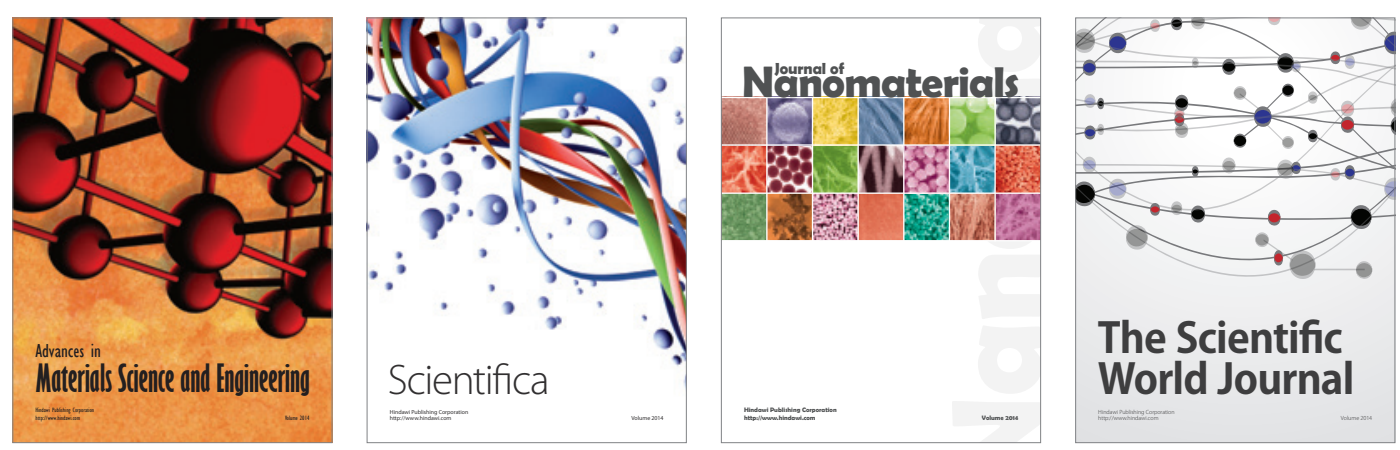

\section{The Scientific World Journal}
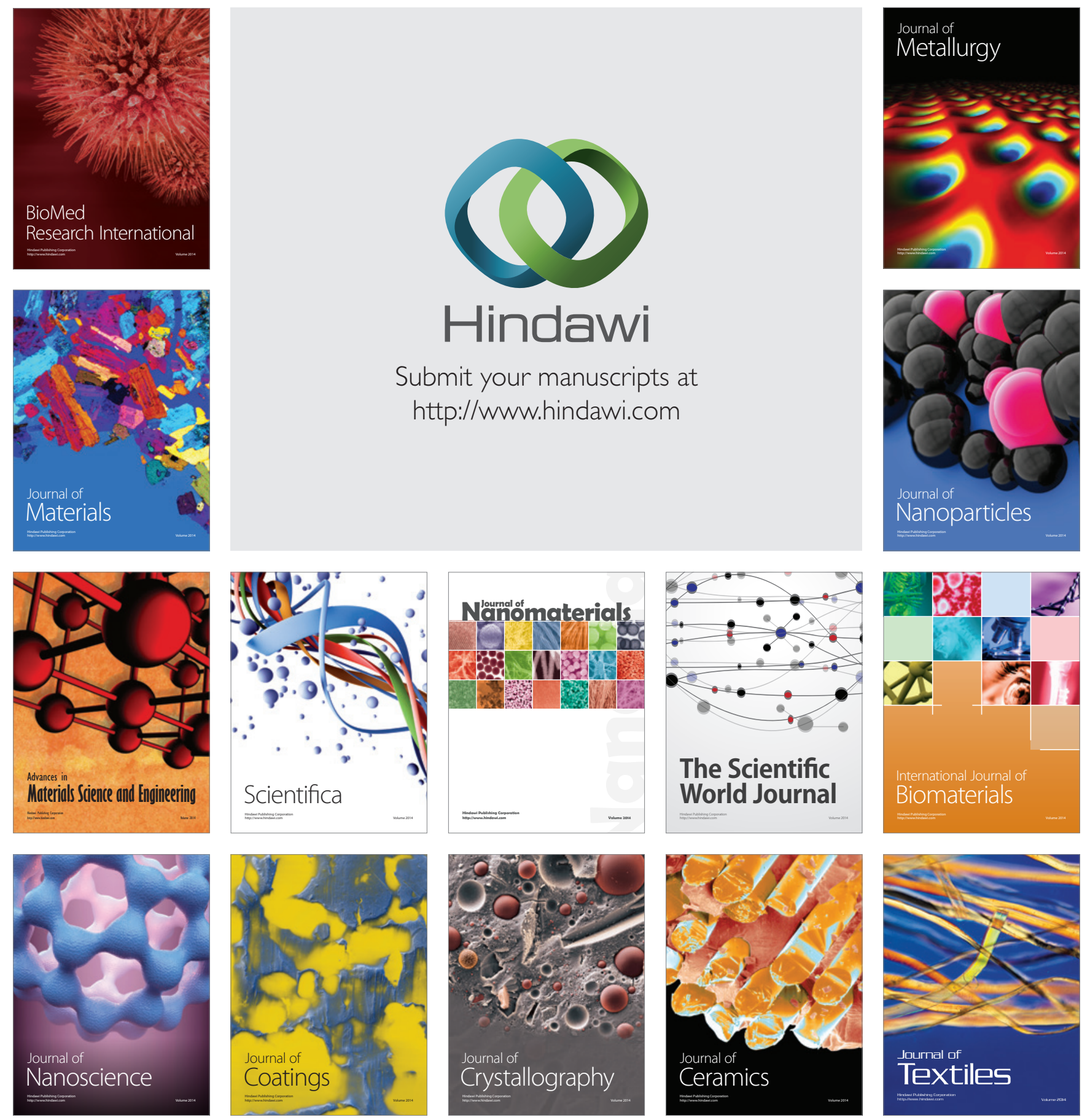